\title{
The effect of Using the Constructive Learning Strategy 7, ES on the Level of Skill Performance of the Skill of 200 Meters Hurdles for Middle School Students in the State of Kuwait
}

\section{*Dr/ Hessa Howeidi Lafta Nashi Al-Osaimi}

Introduction and research problem:

Education in Egypt has now become linked to the transition to the future, from passive education to positive education, and from the role of an indoctrinated teacher to an active mediator role, and states have played an important role in leading the educational process, financing and controlling it, and society has become its partner, as the classes of society of all their types They are the beneficiaries of its outputs, and thus this is reflected in its components (teachers, learners, curricula, methods and teaching methods), which consequently affects every educational institution turning into a center of radiation to unload experiences, abilities, talents and acquire skills.

The time has come for all education workers to join hands in order to benefit Egypt with the development of modern science and knowledge, leaving the focus on preservation, indoctrination and traditional teaching methods that are not in line with the requirements of the times, and are interested in educational strategies and their modern teaching methods in order to prepare the citizen for productive work while clearing his place for him. Suitable for innovative and creative thinking. $(21: 12,13)$

Hasan Hussein Zaitoun and Kamal Hussein Zaitoun (2003 AD) mention that the constructive learning model works to link science with culture and society and seeks to help students build their scientific concepts and knowledge through four stages drawn from the three stages of the learning cycle (exploring the concept - extracting the concept - applying the concept) These four stages are the advocacy stage, the exploration stage, the suggestion of

Physical Education Instructor - Ministry of Education - in the State of Kuwait. 
interpretations and solutions, and the decision-making stages (4: 440)

It also shows that the constructive learning model aims to make the student the focus of the educational process, as it discusses the problem and collects the information that he sees that may contribute to solving the problem, then discusses the proposed solutions with his colleagues, then studies the possibility of applying these solutions in a scientific way, and the student is considered according to this philosophy, discovering what she learns. Through his practice of scientific thinking and he is a researcher of the meaning in addition to being the one who builds his knowledge and participates in the responsibility of managing and evaluating learning, he is more active researcher and prospector to discover appropriate solutions to the problems he faces, and it is the focus of this model and the focus of his attention. Learning and a backup source of information if necessary and a model from which the student can gain experience to notice him first and then assign them to do some tasks in front of him and under careful observation from him, then each of them goes to work on his own most of the time after that to provide him with the learning tools and devices required to complete the learning tasks in cooperation with them. Participate in the process of managing and evaluating learning (16: 7-18(

In this regard, Khairy Al Maghazi, Deir Ajaj (2000 AD), Zainab Omar, and Wafa Mafrej (2009 AD) indicate that in the constructive learning model, students are helped to build their scientific concepts and knowledge. This model also emphasizes linking science with culture and society. The four stages of the model are built on The methods by which the specialists in science and mastery learn and work, and these four stages have two aspects, namely science and culture, and with the difference in the field of study and its subject in terms of being a science or culture, but the course of the lesson is the same, noting the great overlap and interaction between the two sides (5: 108,107) (7) : 438-441)

And at the beginning of the third millennium, it was 
found that the reality of students made it imperative that they use modern methods of learning that combine them with the psychological and social needs of students, and develop in them the desired behaviors, which they desperately need in their dealings inside the classroom and in the community. Educational psychologists and curricula have indicated the most important Modern methods in the learning process, including the Seven E's structural learning dimensions. (6: 9) (74:12)

The seven-stage learning dimension cycle model or the Seven E's structural model is considered one of the modern constructive models, and the teaching method used in the Seven E's structural model or the sevenstage learning dimension cycle includes seven steps, which is excitement, and the aim of this step is to motivate students And to stimulate their curiosity, Exploration, and the goal of this step is to satisfy the curiosity by providing experiences to the pupils and cooperation to realize the conceptual meaning, the explanation / clarification, and the goal of this step is to clarify the concept and define the terms, expansion (detailed thinking), and the goal of this step is to discover new applications The concept, Extension, and the goal of this step is to clarify the relationship between the concept and other concepts, exchange, to change Exchanging, and the aim of this step is to exchange ideas or experiences, the Examination, and the aim of this step is to evaluate the learning and understanding of the pupils. (18:20) (15: 56-59) "Jaber Abdul Hamid" (2006 AD) states that the educational environment for the university stage requires the teaching staff to make double efforts due to the high age of education for female students because of some physical, skill and psychological problems that characterize this stage, which necessitated attention to all factors that help to raise the level of skill performance For the student and keep up with modern technologies, to learn the skillful performance of gymnastics by using modern teaching methods appropriate to the abilities of female students, and the most efficient methods and teaching methods 
are the most economical of effort and time. (90: 2)

Muhammad Abd alGhani (2003 CE) and Muhammad Shehata (2003 CE) indicates that learning motor skills is a complex process that aims at transferring from the teacher to the student (the educated individual) as well as in the changes that occur in the motor behavior, which mainly result from the process of mental practice as it aims It also aims to provide the student (the individual teacher) with physical attributes, motor abilities, skill and planning. (19: 124) (52:17)

As far as the researcher knows, and through her readings and access to many previous studies, such as the study of Hussam al-Din Nabih Abd al-Fattah (2005 AD) (3) entitled the effect of constructive learning on the cognitive and emotional field and the level of skillful performance of handball, and the study of successful bribes on (2013) (8) Entitled "The Impact of Using the Building Learning Model on Learning Some Motor Skills for Gymnastics for Female Students of the College of Physical Education - Minya University, and Sumaya
Mustafa Ahmad (2001) (9) study entitled" Building Learning Strategy and its Impact on Teaching Basketball Skills and Some Knowledge Outcomes for Female Students of the College of Physical Education For Girls in Cairo, and Shaima Hassan Taha's study (2004) (10) entitled Modern Technologies and their Impact on Back-Swimming Learning Outcomes, published research, College of Physical Education for Girls, Helwan University, and Nour Taha Ibrahim's study (2014 AD) (22) entitled the effect of using the cycle of learning dimensions 7 Modified structural ES on the level of learning some motor skills on the ground movement system of middle school students, and the study of Hala Kamel Qasim (2013) (23) entitled the effect of using the modified structural ES 7 dimension course at the level of The skillful performance of some complex offensive skills among the junior karate I found that the modified structural learning dimension cycle ES 7, and none of the researchers mentioned its use in learning field and track skills, and the results of those research and studies have unanimously agreed on the great role that 
this model plays in the success of the educational process Therefore, this research is an attempt to identify the effect of using the 7 , es constructive learning strategy on the level of skill performance of 200 meter barriers for intermediate school students in the State of Kuwait.

\section{Research goal}

Identify the effect of using the 7 , es constructive learning strategy on the level of skill performance for the skill of 200 meters hurdles for middle school students in the State of Kuwait.

\section{Research hypotheses}

-There are statistically significant differences between the mean of the pre and post measurements in the level of learning the skill of the 110meter hurdles competition.

Some of the terms included in the search

\section{The Constructivist Learning} Style

It is "one of the methods that is based on constructivism and consists of four successive phases (advocacy, exploration, suggesting interpretations and solutions, taking action) and each stage performs a specific function that is a preparation for the next phase." The call stage leads students to push for research and exploration, and in the exploration phase they search Students on all that was presented to them in the advocacy stage and in the stage of proposing solutions and explanations, the teacher leads his students to reach the required concepts or relationships through their explanations and suggestions that he arrived at in the exploration stage and in the action stage, and what was reached in the stage of suggesting explanations is applied (25:37) - 40)

\section{Seven E's Learning Dimensions 7, Modified Constructivist ES course:}

It is an educational model consisting of seven instructional steps that the teacher uses with his pupils within the lesson and aims for the student to build his scientific knowledge by himself, in addition to developing many different concepts and skills. This model depends on excitement, curiosity, exploration, interpretation, expansion, linking concepts and modifying some misconceptions they have and correcting them (7: 152)
Research
plan procedures:
Research Methodology:

and 
The researcher used the experimental method due to its suitability to the nature of the current research by using the experimental design of an experimental group by following the pre and post measurement.

\section{Research Community and Sample:}

The

research community represented the middle school students in the State of Kuwait, the ninth division in the Jahra Governorate during the academic year 2019/2020, the second semester, and the research community reached (66) students. Basic in addition to (8) students to conduct an exploratory study to research and use the constructive learning model with them to learn some motor skills on the skill of 110 barriers that are prescribed to them during the school year.

Conditions for selecting the research sample

The student must be from the ninth year in the middle school because of their study of the four technical devices.

-The knowledge experience of the research sample is understood in the undergraduate stage.

-Regularity of the research sample in the presence of the proposed educational program.

Moderation of Frequency Distribution and Equivalence of the Sample:

\section{Table (1)}

The arithmetic mean, median, standard deviation, and convolution factor for growth rates and physical variables $\mathbf{N}=\mathbf{2 8}$

\begin{tabular}{l|c|c|c|c|c}
\hline \hline Variables & $\begin{array}{c}\text { measuring } \\
\text { unit }\end{array}$ & SMA & Mediator & $\begin{array}{c}\text { standard } \\
\text { deviation }\end{array}$ & $\begin{array}{c}\text { Coefficient } \\
\text { of torsion }\end{array}$ \\
\hline \hline Age & Year & 22.18 & 22.20 & 0.011 & 0.0 .314 \\
\hline Height & $\mathrm{Cm}$ & 163.28 & 163.00 & 4.36 & 0192 \\
\hline Weight & $\mathrm{Kg}$ & 54.51 & 54.50 & 2.54 & 0.011 \\
\hline \hline Running $30 \mathrm{~m}$ & $\mathrm{~S}$ & 5.98 & 5.90 & 0.54 & 0.62 \\
\hline Grip strength & $\mathrm{Kg}$ & 9.15 & 9.10 & 0.12 & 0.52 \\
\hline $\begin{array}{l}\text { Back muscle } \\
\text { strength }\end{array}$ & $\mathrm{Kg}$ & 38.94 & 38.90 & 0.45 & 0.14 \\
$\begin{array}{l}\text { The strength of } \\
\text { the two leg } \\
\text { muscles }\end{array}$ & $\mathrm{Kg}$ & 33.98 & 33.90 & 0.47 & 0.39 \\
\hline $\begin{array}{l}\text { Arm muscle } \\
\text { capacity }\end{array}$ & $\mathrm{M}$ & 1.22 & 1.20 & 0.63 & 0.54 \\
\hline \hline
\end{tabular}


Follow Table (1)

The arithmetic mean, median, standard deviation, and convolution factor for growth rates and physical variables $N=28$

\begin{tabular}{l|c|c|c|c|c}
\hline \hline Variables & $\begin{array}{c}\text { measuring } \\
\text { unit }\end{array}$ & SMA & Mediator & $\begin{array}{c}\text { standard } \\
\text { deviation }\end{array}$ & $\begin{array}{c}\text { Coefficient } \\
\text { of torsion }\end{array}$ \\
\hline \hline $\begin{array}{l}\text { Leg muscle } \\
\text { capacity }\end{array}$ & $\mathrm{Cm}$ & 26.98 & 26.90 & 0.25 & 0.32 \\
\hline $\begin{array}{l}\text { The endurance of } \\
\text { the abdominal } \\
\text { muscles }\end{array}$ & $\mathrm{No}$ & 22.98 & 22.90 & 0.78 & 0.74 \\
\hline $\begin{array}{l}\text { Spine flexibility } \\
\text { Static poise }\end{array}$ & $\mathrm{Cm}$ & 5.20 & 5.00 & 0.32 & 0.36 \\
\hline Agility & $\mathrm{S}$ & 8.65 & 8.50 & 0.51 & 0.17 \\
\hline $\begin{array}{l}\text { Shoulder joint } \\
\text { flexibility }\end{array}$ & $\mathrm{Cm}$ & 10.65 & 10.50 & 0.58 & 0.025 \\
\hline \hline
\end{tabular}

It is evident from Table (1) that the torsion coefficients ranged between $(0.025,0.323)$, meaning that they were confined to $(+3,-3)$, indicating that they are located inside the equilibrium curve, and thus the sample is moderately distributed, indicating the homogeneity of the sample.

Table (2)

The arithmetic mean, median, standard deviation, and convolution factor of the variables the level of skill performance in the competition of 110 hurdles $N=28$

\begin{tabular}{|c|c|c|c|c|c|}
\hline Variables & $\begin{array}{c}\text { measuring } \\
\text { unit }\end{array}$ & SMA & Mediator & $\begin{array}{l}\text { standard } \\
\text { deviation }\end{array}$ & $\begin{array}{c}\text { Coefficient } \\
\text { of torsion }\end{array}$ \\
\hline $\begin{array}{l}\text { Beginning } \\
\text { and } \\
\text { approaching } \\
\text { the first } \\
\text { checkpoint }\end{array}$ & Degree & 1.11 & 1.10 & 0.12 & 0.249 \\
\hline $\begin{array}{l}\text { Step and } \\
\text { baffle barrier }\end{array}$ & Degree & 1.05 & 1.00 & 0.11 & 1.363 \\
\hline $\begin{array}{l}\text { The running } \\
\text { between the } \\
\text { barriers }\end{array}$ & Degree & 1.12 & 1.10 & 0.14 & 0.428 \\
\hline $\begin{array}{l}\text { Sprint from } \\
\text { the last } \\
\text { barrier until } \\
\text { the end of } \\
\text { the race }\end{array}$ & Degree & 1.14 & 1.10 & 0.13 & 0.923 \\
\hline
\end{tabular}


It is evident from Table (2) that the torsion coefficients ranged between $(1.363,0.249)$, that is, it was confined between $(+3,-3)$, indicating that it is located inside the equinox curve, and thus the sample is moderately distributed, indicating the homogeneity of the sample to the level of 110 baffles.

\section{Data collection tools}

\section{1- Records:}

The students' affairs records at the Jahra Educational Administration and enrolled in the school records for the first academic year 2019/2020 were used to obtain data on the research sample individuals in terms of the number of students in the study sample.

\section{2- Forms}

\section{A- Registration forms:}

The researcher designed a form to record the results of the exams under study.

B - Expert opinion survey form on the content of the proposed program.

The researcher presented a questionnaire for expert opinion polls on the content of the proposed program using the constructive learning strategy program period - number of units per week - unit time.

$-r$ Research tools

\section{First: devices and tools}

Alrustameter device for measuring height and weight chalk - tape measure stopwatch - balloons - plastic balls - rings - ropes - suede seats - cones - mattresses.

Second: The tests used for research:

\section{)A) Physical exams- :}

Running test (30) meters from high start to measure the level of speed.

- Dynamo meter to measure muscle strength, "grip strength."

- Dynamo meter to measure the strength of the back muscles.

- Dynamo meter to measure the strength of the leg muscles.

Throwing a medical ball to the farthest distance to measure the muscular capacity of the arms.

A test of the vertical jump from stability to measure the muscle capacity of the two men.

- Lifting the trunk up from lying test to measure the muscular endurance of the abdominal muscles.

The torso lift test is to measure the flexibility of the spine.

Stand test on balance plate to measure static balance.

- $\quad$ Shuttle running test to measure agility.

- Shoulder joint flexibility test from the horizontal position to measure shoulder flexibility.

)B) skill tests:

The researcher designed a questionnaire to measure the skill level of the 
skill of 110 hurdles and presented it to the referees in the field of the field and the track. The evaluation was individually for each arbitrator under consideration. The form was presented to (3) of the arbitrators and the average bikes were taken for each student. Attachment (3(

\section{Third: Learning Dimensions 7} course, modified structural ES

The researcher used the modified structural learning dimension cycle ES 7 model according to what was referred to by "Hussam Al-Din Nabih (2005) (3),“ Rasha Najeh "(2013) (8) Magdy Ibrahim (2002) (15), Smart Ibrahim Qass, Adel Mahmoud AbdelHafez (2000 AD) (6), which were represented in the following steps:

\section{( 1 Provide explanatory data.}

$(r)$ Presenting questions that lead to feelings or the need for research and exploration, or an incomplete or disorganized educational material or contradictory information, which have been formulated as keys to a solution that leads the student to gradually discover the final result (movement.(

( $r)$ If there is more than one possible response, the teacher must be prepared with another key to guide the learner to choosing one only and leave the rest by presenting an additional key or question.

(₹) Each step builds on the response achieved in the previous step.

( $)$ In case of deviation from the detection process, the parameter will repeat the question or key that precedes the incorrect response.

( 7 In the event that the incorrect response continues, the teacher intervenes and presents another question that represents a small step to help the learner.

( $v)$ She gives the student a continuous feedback with the word yes, nodding, or the word "true", or continues questions that show him that he is on the right path.

$(\wedge)$ The teacher does not give the learner the answer at all.

( 9 ) Verbal behavior can be used such as: Did you follow your answer? Or would you like to think more?

(1.)A clause to remind the student that when he fails to discover what is required of him, he has the capabilities that enable him to research.

( ) Instructions to provide the student with them.

(I) Instructions to clarify when he is required to try again. 
4- Design worksheets in the learning model and illustrated guide:

The researcher followed the following steps:

A- The researcher designed the worksheets for the constructivist learning model, which is the method that was used in the implementation of the constructive learning model work, and there are:

(1) Pictures or illustrations that lead to the feeling or the need for research and exploration, and were formulated as solution keys that lead students to gradually discover the final result (skill)

$(r)$ If there is more than one possible response, the teacher must be prepared with another key to guide students to choosing only one and leave the rest by presenting an additional key or question.

( $r)$ Each step builds on the response achieved in the previous step.

( $\varepsilon)$ In the event of deviation from the discovery process: The question or key that precedes the incorrect response is repeated by the teacher.

$(0)$ In the event that the incorrect response continues, the teacher intervenes and presents another question that represents a small step to help learning.

( 7 The teacher gives continuous feedback with a yes word, a nod to the head, or a correct word, or continues questions that show the learner that he is on the right path.

$(\vee)$ The teacher does not give the answer to the learner at all.

(^)Verbal behavior can be used such as: Did you follow your answer? Or would you like to think more?

(9)A clause to remind the student that when he fails to discover the wanted, he has the capabilities that enable him to research.

Implementing the work using the modified Constructivist ES 7, Learning Dimensions cycle model:

The main stages of the modified Structural Learning Dimensions 7, ES 7 cycle model have been taken into consideration in its implementation as follows:

*The excitation (activation) phase:

At this stage, the researcher stimulates the student and raises their curiosity and interest in a specific topic through dialogue with them about the importance of these skills, their method of performance, and their constructive points with mentioning the legal aspects of the skill and the performance of a model or presentation of some slides of the skill.

\section{*The exploration phase:}

In this stage, the researcher satisfies the curiosity and curiosity of the students by 
providing them with experiences to understand how to perform, and in it the final form of the skill is discovered by displaying the skill through educational pictures or its performance by the students with a good level in the field and the field in order for the student to try Gain the proper steps for the performance and try to draw this image in his mind.

Interpretation stage (clarification:)

At this stage, the researcher clarified and explained the skill to be learned and tries to shed light on the technical points affecting the skill under investigation.

\section{*The expansion phase:}

At this stage, the researcher supervised the method of performance of the skills under investigation, linked the skills to each other, found a logical sequence of the skill and tried to perform it in a proper manner without interference by the researcher.

*The extension phase:

In this stage, the researcher supervised the students as they performed the skills and clarified the relationship and connection between the skills and some of them.

\section{*The exchange stage:}

At this stage, the researcher supervised the students as they exchanged or changed ideas and experiences and gathered interesting participation through various activities.

\section{Examination stage (evaluation)}

At this stage, the researcher assessed the students 'performance level for the skills under investigation through direct observation of the performance inside the field and track court.

\section{Time period of the experiment- :}

The experiment was applied in the time period from $10 / 15 / 2019$ to $6 / 12 / 2019$ over a period of (8) weeks, with two educational units per week of (90) minutes, i.e. (1440) minutes, with a total of (16) units.

The unit time was distributed as follows:

Administrative work and warm-up (10)

Special physical preparation (25) The main part of the constructivist learning model (50) Closing parts (5)

\section{Educational content:}

The researcher prepared (8) educational units using the constructive learning model. The following is the 
educational content for each unit of the program.

- The first and second educational unit: the beginning and approaching the first checkpoint.

- The third and fourth educational units: Step and Markets Barrier.

The fifth and sixth educational units: the enemy between barriers.

-Units Seven and Eight: Sprint from the last checkpoint until the end of the race.

\section{The second exploratory experiment- :}

The researcher conducted an exploratory experiment on (16) students from the same research community from the study sample on 11/10/2019 and the aim of the exploratory experiment was- :

A - Students' use of the motor skills to race 110 hurdles to verify their ability to implement the skills well and apply some of the suggested exercises for special physical preparation.

B - Training the work team (aid from outstanding students) to play their role when implementing the experiment in terms of identifying the exercises used in the program.
C- Identify the difficulties that the researcher may face when implementing the experiment. The results of the pilot experiment confirmed- :

A- Students' ability to perform more closely to the correct performance.

B- the efficiency of aid to fulfill their role.

C- Safety and validity of devices and tools.

Tribal measurements:

Pre-measurements were made for each to which the structural learning model was applied with the structural ES 7 strategy in the study variables from $10 / 13 / 2019$ to $10 / 14 / 2019$ as follows:

a.Anthropometric measurements, which included measurements of (height - weight) 10/13/2019 for the research sample.

B. Skill measures by the referees committee of the field and track.

\section{Basic experience:}

The basic experiment was carried out on $10 / 15 / 2019$ to $6 / 12 / 2019 \mathrm{AD}$, the researcher taught, at the rate of two units per week according to the time plan specified for the educational unit for the skills of 110 barriers, where the skill was taught according to the constructive learning model in its seven stages, and the researcher took care when teaching to provide a period of 
time Sufficient to perform mental operations and not to rush to perform the skill dynamically, and not to underestimate the value of the student's response to the movement even if it is far from the correct performance. Rather, it is met by convergent questions graduated in the same right direction to respond to the movement with the encouragement of correct responses in order for the student to gain confidence in themselves. For dialogue and discussion during the different stages of the constructive learning model and working on an exchange of opinion to extract the final form of performance.

Post measurements:
After completing the application of the experiment, the post measurements of the research sample were performed in the variables under study under the same conditions that were made in the pre-measurements and in the same order and conditions, 8-9 / 12/2019 AD and after the completion of the post measurements, the data were unloaded and prepared for statistical treatment.

-The statistical treatments used in the study:

Mean

Standard Deviation

Medium

Skewers torsion modulus

- The percentage of change rates between tribal and posttribal Presentation and discussion of results

Table (3)

The indication of the differences between the pre and post measurement in the level of skillful performance of the 110 hurdles race $N=20$

\begin{tabular}{c|c|c|c|c|c|c|c|c|c}
\hline \hline $\begin{array}{c}\text { Skill } \\
\text { variables }\end{array}$ & \multirow{2}{*}{$\begin{array}{c}\text { measuring } \\
\text { unit }\end{array}$} & \multicolumn{2}{c|}{$\begin{array}{c}\text { Pre } \\
\text { measurement }\end{array}$} & \multicolumn{2}{c|}{$\begin{array}{c}\text { Post } \\
\text { measurement }\end{array}$} & $\begin{array}{c}\text { Differences } \\
\text { between the } \\
\text { two averages }\end{array}$ & $\begin{array}{c}\text { Improvement } \\
\text { percentage }\end{array}$ & $\begin{array}{c}\text { Value } \\
\text { (t) }\end{array}$ & $\begin{array}{c}\text { Indication } \\
\text { level }\end{array}$ \\
\hline $\begin{array}{c}\text { Ineginning } \\
\text { and } \\
\text { approaching } \\
\text { the first } \\
\text { checkpoint }\end{array}$ & Degree & 1.11 & 0.12 & 2.26 & 0.18 & 1.15 & $50.88 \%$ & 4.65 & Sin \\
\hline $\begin{array}{c}\text { Step and } \\
\text { baffle } \\
\text { barrier }\end{array}$ & Degree & 1.05 & 0.11 & 2.25 & 0.66 & 1.20 & $53.33 \%$ & 5.29 & Sin \\
\hline $\begin{array}{c}\text { The } \\
\text { running } \\
\text { between the } \\
\text { barriers }\end{array}$ & Degree & 1.12 & 0.14 & 2.21 & 0.13 & 1.09 & $49.32 \%$ & 4.66 & Sin \\
\hline $\begin{array}{c}\text { Sprint from } \\
\text { the last } \\
\text { barrier until } \\
\text { the end of } \\
\text { the race }\end{array}$ & Degree & 1.14 & 0.13 & 2.31 & 0.54 & 1.17 & $50.64 \%$ & 4.85 & Sin \\
\hline \hline
\end{tabular}

The tabular $(\mathrm{t})$ value at a degree at the level of significance $(0.05)=1.812$ 
It is evident from Table (3) that there are statistically significant differences between the averages of the tribal and post measurements in the level of skill performance of the 110 hurdles race and in favor of the post measurement where the tabular value of $(\mathrm{T})$ was greater than its calculated value at the level of significance $(0.5)$

\section{Discuss the results}

It is evident from Table (6) that there are statistically significant differences between the averages of the pre and post measurements in the level of skillful performance of the students of the field and the technical field and in favor of the post measurement where the tabular value of ( $t$ ) was greater than its calculated value at the level of significance (0.5) and the researcher returns that result to The application of the modified structural learning dimensions ES 7 cycle model, which is characterized by providing information in an integrated manner and in a logical order in frameworks that take into account the principles and theories of effective teaching in that it takes into account the mental capabilities of learners and urges learning to think and research in accessing knowledge, which makes the learner's role effective in the process It also makes the learner more interesting, interesting and exciting, which makes the learning process more enjoyable, and this is consistent with what was indicated by "Davy, T. Johnson, Duffy, T. \& Jonassen, D." (2004 AD) that the formative learning model provides the opportunity for Learners to think of as many solutions as possible to a single problem (25:72)

The results of the study of "Hala Qasim" (2013) (23) also indicate the effectiveness of the seven-stage learning cycle model in the learning process positively on their research samples. The researcher indicates that these results are due to the application of a new learning method, which is the sevenstage learning cycle model. The stages, during which the learning is active and the role of the learner is positive and the learner is motivated to learn, taking into account the individual differences in the strategy of the Structural Learning Dimensions 7, ES 7 cycle, which is modified for its reliance on the self-experience of the learners so that the 
learner is the focus of the educational process as it makes the learner search and remember previous knowledge, discover and implement this Consistent with what was indicated by "Hala Qassem" (2013 AD) (23) and "Amr Abdullah" (2004 AD) (14), whose most important results indicated that the use of the seven-stage learning dimension cycle model affected learners from multiple aspects such as thinking Finding mistakes, finding solutions, and learning. The learner is considered the focus of this model and the focus of his attention. As for the teacher's role, it is the organizer of the learning process, which is the wave of the tasks that the learners carry out under his supervision and direction. Thus, he participates in the process of managing and evaluating learning.

Stephen steven (2005 $\mathrm{AD})$ adds that it is necessary for the student to be familiar with the latest methods and modern technologies that enable them to deliver knowledge to learners and create better areas for improving the teaching and learning process, and from here the importance of choosing the appropriate teaching method to achieve the desired goal, and this choice depends on the teacher's experience And the extent of his awareness of the nature, components and variables of different educational situations (37:26)

This is consistent with the results of the study of "Hala Qasim" (2013 CE) (23) and "Rasha Nahij Ali (2013 CE)" (8) that the use of the modified structural learning dimension cycle ES 7 model works to motivate learners and arouse their curiosity and interest in a specific topic And their active participation, in which the role of the teacher is to create excitement, generate curiosity towards learning, raise questions, encourage prediction, extract responses that reveal what the learners have from previous information and experiences, or how they think about the skills in question.

" Mohamed El-Sayed" (2007) asserts that the sevenstage learning model provides an opportunity for learners to think, search for information and become familiar with it, which helps them reach the optimal solution to the problems they may face (80: 20) 
Magdy Ibrahim (2002) points out that in order for the teacher to push his students to learn, he must use different and multiple methods and methods, which requires the teacher to be fully conversant with the different teaching methods and methods, how learning occurs on the part of students, and how the methods and methods used affect the speed Achieving the goal of the teaching and learning process. (21:15)

Aisha Muhammad AlFateh (2005 AD) indicates that in order for the teacher to push his students to learn, he must use different and multiple methods and methods, which requires the teacher to be fully conversant with the different methods and methods of teaching and how learning occurs on the part of students and how the methods and methods used in The speed of achieving the goal of the teaching and learning process. (21:11)

Stephen steven (2005 $\mathrm{AD})$ adds that it is necessary for the student to be familiar with the latest methods and modern technologies that enable them to deliver knowledge to learners and create better areas for improving the teaching and learning process. Hence, the importance of choosing the appropriate teaching method to achieve the desired goal, and this choice depends on the teacher's experience and the extent of His awareness of the nature, components and variables of different educational situations (37:26)

This also agrees with the study of Aisha Muhammad Al-Fateh (2005 AD) (11) and Nour Taha Ibrahim (2014 AD) (22) which indicates the effectiveness of constructive learning, which leads learners to interact with this method and challenge them to themselves and discover solutions to problems and questions presented to them to reach To learn the skills under their research.

Thus, the hypothesis of the research has been fulfilled, which states that there are statistically significant differences between the averages of the pre and post measurements in the level of learning some motor skills at the level of 110 barriers.

Conclusions and recommendations: First: the conclusions

In light of the research results, the researcher reached the following conclusions: 
-The use of the seven-stage learning dimension cycle model contributed positively to learning some of the field and track skills under discussion.

-The use of the seven-stage learning dimension cycle model contributed positively to learning some of the previous 110 barriers under discussion.

\section{Second: Recommendations}

In light of the research results, the researcher recommends the following:

1- The necessity to use the seven-stage learning dimension cycle model in learning field and track skills.

2- Inviting those in charge of the educational process in the field of physical education in general and field and track sports in particular by encouraging the use of the learning dimension cycle model.

3- Conducting research and studies using the sevenstage learning dimension cycle model for other activities skills on other variables and samples.

\section{References}

1-Adeel Saad Shenouda, Samia Farghali Mansour (2001 AD): Artistic Gymnastics (Concepts and Applications) ", Thought Forum for Publishing, First Edition, Alexandria.
2-Aisha Muhammad AlFateh (2005 AD): "The Effectiveness of Using Building Learning on Cognitive Concepts and the Performance Level of Some Attacks in Fencing Sports" Unpublished PhD thesis, College of Physical Education for Girls, Helwan University, Cairo.

3-Ayesh Zaitoun Al-Mawla (2007 AD): Constructivist Theory and Strategies for Teaching Science, Dar AlShorouk, Cairo.

\section{4- Ali Abdel-Majeed (2000}

AD): "A proposed teaching strategy based on the constructive learning model and its effect on the kinetic innovation of elementary school students, published research, Scientific Journal of the College of Physical Education for Boys, Helwan University, Issue 33, April, Cairo.

5- Amr Abdullah AbdelQader Hussein (2004 AD): "The Impact of Formative Learning in Teaching Basic Skills for Basketball”, unpublished $\mathrm{PhD}$ thesis, College of Physical Education for Boys, Helwan University.

6-Jaber Abdel-Hamid (2006 AD): Contemporary Trends and Experiences in Evaluating 
Student and Teacher Performance, House of Arab Thought, Cairo.

7- Hala Kamel Qasim (2013 AD): "The effect of using the modified structural learning dimensions course 7, ES on the level of skill performance of some complex offensive skills among karate juniors, published scientific research, Journal of Sports Sciences and Arts, College of Physical Education for Boys, Helwan University.

8-Hossam El-Din Nabih Abdel-Fattah (2005 AD): "The Impact of the Formative Learning Method on the Cognitive and Emotional Domain and the Level of Skill Performance of Handball" $\mathrm{PhD}$ Thesis - College of Education Al-Azhar University, Cairo.

9-Hassan Hussein Zaitoun, Kamal Hussein Zaitoun (2003 AD): "Education and Teaching from the Perspective of Constructivism Theory" The World of the Book, Cairo.

10- Magdy Aziz Ibrahim (2002 AD): Effective Teaching - What It Is - Skills Administration - The AngloEgyptian Library, Cairo.

11- Muhammad Ibrahim Shehata (2000 AD): Foundations of Teaching
Gymnastics, 1st Edition, Dar Al Fikr Al Arabi, Cairo.

12- Muhammad Ibrahim Shehata (2003 AD): "Training for Contemporary Gymnastics", Dar Al Fikr Al Arabi, Cairo.

13- Muhammad Ibrahim Shehata (2006 AD): Fundamentals of Sports Training. Egyptian Library, Publishing, Alexandria.

14- Muhammad AbdulGhani Othman (2003 AD): Kinetic Learning and Sports Training, Second Edition, Dar Al-Qalam, Kuwait.

15- Muhammad Ali Al-Sayed (2002 AD): Teaching Aids and Educational Technology, 2nd Edition, House of Arab Thought, Cairo.

16- Makarem Helmy Abu Harjah, Muhammad Saad Zaghloul Mahmoud and Hani Saeed Abdel Moneim (2001). Problems of Physical Education Curricula, School of Diagnosis and Treatment, AlKitab Center for Publishing, Cairo.

17- Nour Taha Ibrahim: (2014 AD): The effect of using the modified structural learning dimensions course ES 7 on the level of learning some motor skills on the ground movements system of middle school students, published 
scientific research, The Scientific Journal of Physical Education and Sports Sciences, College of Physical Education for Boys , Helwan University. 18-Khairy Al Maghazi, Deir Ajaj (2000 AD): "Methods of Thinking and Learning", a comparative study, The Egyptian Anglo Library, Cairo. 19-Rasha Najeh Ali (2013 AD) "The effect of using the constructive learning model on learning some motor skills for gymnastics for students of the Faculty of Physical Education Minia University, published scientific research, Journal of Physical Sciences, College of Physical Education, Minia University.

20-Smart Ibrahim Qas, Adel Mahmoud Abdel-Hafez (2000 AD): Teaching Methods in Physical Education, Al-Radaa Artistic Library and Printing Press, Alexandria.

21-Sumaya Mostafa Ahmed (2001 AD): "The Building
Learning Strategy and its Impact on Teaching Basketball Skills and Some Knowledge Outcomes of the Female Students of the College of Physical Education in Cairo" Published Research, The Scientific Journal of Physical Education and Sports, Issue Thirty-Eight, Cairo.

22-Shaimaa Hassan Taha AlLaithi (2004): Modern techniques and their impact on learning outcomes for backstroke, published research, College of Physical Education for Girls, Helwan University, Journal of Sports, Sciences and Arts, Volume Twenty, First Issue, January.

23-Zainab Ali Omar and Wafa Muhammad Mufaraj (2009 AD): "Practical Applications in Teaching Methods of Physical Education" House of Modern Book, Cairo. 